CZASOPISMO INŻYNIERII LĄDOWEJ, ŚRODOWISKA I ARCHITEKTURY JOURNAL OF CIVIL ENGINEERING, ENVIRONMENT AND ARCHITECTURE

JCEEA, t. XXXIII, z. 63 (4/16), październik-grudzień 2016, s. 247-254

Jakub JURA ${ }^{1}$

Małgorzata ULEWICZ ${ }^{2}$

\title{
WPLYW DODATKU MATERIAŁÓW ODPADOWYCH Z TWORZYW POLIMEROWYCH NA WYBRANE PARAMETRY MECHANICZNE ZAPRAW CEMENTOWYCH
}

\begin{abstract}
W artykule krótko scharakteryzowano problematykę zwiększającej się ilość odpadów oraz problemów z ich zagospodarowaniem, wykorzystaniem oraz recyklingiem. Przedstawiono doniesienia literaturowe o badaniach laboratoryjnych oraz na większą skalę możliwości ponownego wykorzystania w budownictwie odpadów budowlanych, a także odpadów pochodzących z innych sektorów gospodarki. W części doświadczalnej sprawdzono możliwość zastosowania odpadowych tworzyw polimerowych (mieszanina polietylenu 50\% i polipropylenu 50\%) pochodzących z rozdrobnienia zakrętek od butelek przez autorów za pomocą rozdrabniarki. Określono wpływ ilości użytego materiału odpadowego na właściwości fizyczne i mechaniczne próbek tj. wytrzymałość na ściskanie, mrozoodporność, ubytek masy oraz nasiąkliwość powstałych materiałów budowlanych. W badaniach wykonane zostały próbki zaprawy normowej oraz próbki zapraw zawierające rozdrobniony materiał odpadów polimerowych w ilości $10-30 \mathrm{~g}$. Badania wykonano przy pomocy maszyny wytrzymałościowej zgodnie z obowiązującymi normami PN-EN. Z wykorzystaniem mikroskopu skaningowego uzyskano mikrofotografie, a także widma składu pierwiastkowego mikroobszarów powierzchni zapraw. Wykazano, że najwyższą wytrzymałość na ściskanie (59 MPa) uzyskały próbki z zapraw, w których wykorzystano $20 \mathrm{~g}$ polimerowych materiałów odpadowych. Wszystkie próbki zawierające materiały polimerowe uzyskały mniejszy spadek wytrzymałości na ściskanie po badaniach mrozoodporności niż próbki normowe. Najmniejszy spadek wytrzymałości wykazały próbki serii, w których wykorzystano 30 g odpadów. W badanych próbkach najmniejszą nasiąkliwość $(4,79 \%)$ uzyskały próbki zaprawy normowej, jednak pozostałe próbki posiadały bardzo zbliżone wyniki $(4,83 \div 4,92 \%)$
\end{abstract}

Słowa kluczowe: tworzywa polimerowe, gospodarka odpadami, zaprawy cementowe, polietylen, polipropylen

${ }^{1}$ Autor do korespondencji / corresponding author: Jakub Jura, Politechnika Częstochowska, Wydział Budownictwa, ul. Akademicka 3, 42-201 Częstochowa; jura@bud.pcz.czest.pl

2 Małgorzata Ulewicz, Politechnika Częstochowska, Wydział Budownictwa, ul. Akademicka 3, 42-201 Częstochowa; ulewicz@bud.pcz.czest.pl 


\section{Wprowadzenie}

Sektor budowlany zużywa duże ilości surowców naturalnych i energii pochodzącej z zasobów naturalnych, a jednocześnie wytwarza szereg odpadów (5741,6 tys. Mg w 2013 r., dane GUS). Znaczna część wytworzonych odpadów może być wykorzystana bezpośrednio do produkcji materiałów budowlanych. W sektorze budowanym, jak wynika z doniesień literaturowych, istnieje również możliwość wykorzystania odpadów poprodukcyjnych i poużytkowych pochodzących z innych sektorów gospodarki. W skali laboratoryjnej podejmowane są próby wykorzystania do betonów takich materiałów odpadowych jak: materiały rozbiórkowe [1], pustaki ceramiczne [2], ceramika sanitarna [3], włókna i odpady szklane [4], odpady z gumy [5], korek [6] czy popioły ze współspalania biomasy [7]. Badane były również możliwości wykorzystania materiałów polimerowych w betonach [8]. W niniejszym artykule określono możliwość wykorzystania w zaprawach cementowych odpadów w postaci mieszaniny tworzyw polimerowych (polipropylenu i polietylenu). Ilość tego typu odpadów systematyczne wzrasta, co powoduje, że niezbędne jest poszukiwanie nowych proekologicznych technologii ich zagospodarowania.

\section{Część doświadczalna}

$\mathrm{W}$ artykule przedstawiono wyniki badań właściwości mechanicznych zapraw cementowych z użyciem odpadowych materiałów polimerowych. Polimerowe materiały odpadowe użyte do badań pochodziły ze zmielenia zakrętek od butelek z polipropylenu (PP) oraz polietylenu (PE) do frakcji rzędu 0-5,0 mm (rys. 1).

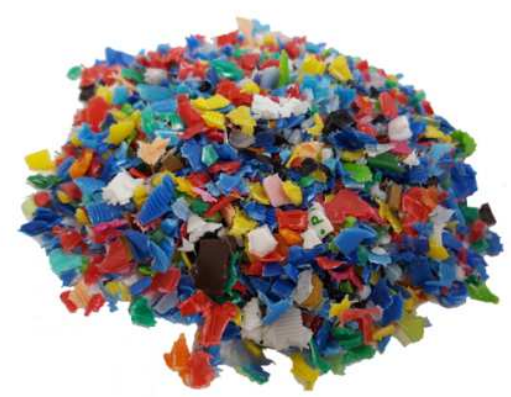

Rys. 1. Tworzywa polimerowe użyte do badań

Fig. 1. The polymeric materials used for research

Skład badanych zapraw cementowych przedstawiono w tabeli 1. Próbki zaprawy normowej (PK), a także zapraw cementowych z użyciem odpadów polimerowych $\mathrm{w}$ ilości $10 \div 30 \mathrm{~g}$ (serie $1 \div 3$ ) wykonano zgodnie $\mathrm{z}$ normą 
PN-EN196-1. Beleczki o wymiarach $4 \times 4 \times 16 \mathrm{~cm}$ wykonano z użyciem cementu portlandzkiego CEM I 42,5 R. Wyroby zostały rozformowane po $24 \mathrm{~h}$ i trafiły do kąpieli wodnej. Po 28 dniach od wytworzenia próbek wykonane zostały badania wytrzymałości na ściskanie na 6 próbkach przy pomocy maszyny wytrzymałościowej Toni Technik typ 2030 zgodnie z normą dla zapraw cementowych oraz mrozoodporność ( 25 cykli zamrażania i rozmrażania). Po wysuszeniu próbek określono także nasiąkliwość zaprojektowanych zapraw oraz wykonano zdjęcia mikroskopowe SEM obrazujące mikrofotografie zapraw cementowych.

Tabela 1. Skład zapraw cementowych - proporcje mieszanek

Table 1. Composition of cement mortars - mixing ratios

\begin{tabular}{|l|c|c|c|c|}
\hline \multirow{2}{*}{\multicolumn{1}{|c|}{ Skład }} & \multicolumn{4}{c|}{ Seria } \\
\cline { 2 - 5 } & PK & $\mathbf{1}$ & $\mathbf{2}$ & $\mathbf{3}$ \\
\hline Cement, g & 450 & 450 & 450 & 450 \\
\hline Woda, cm ${ }^{3}$ & 225 & 225 & 225 & 225 \\
\hline Piasek normowy, g & 1350 & 1350 & 1250 & 1250 \\
\hline Tworzywo polimerowe, g & - & 10 & 20 & 30 \\
\hline
\end{tabular}

Jak wykazała analiza mikroskopowa SEM (rys. 2), struktura powstałych zapraw jest jednorodna, układ składników zaprawy jest bardzo podobny we wszystkich próbkach, a wprowadzone dodatki odpadowe PP i PE wyraźnie widać w strukturze materiału. Analiza widma pierwiastkowego (rys. 3) wykazała że głównymi pierwiastkami kompozytu są krzem, wapń, żelazo, siarka oraz potas i glin.
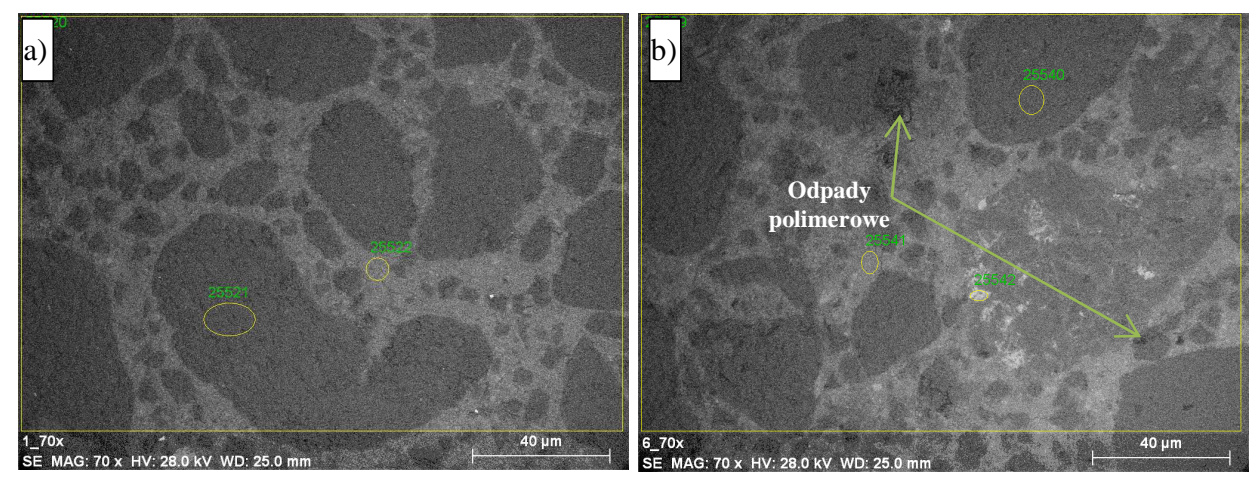

Rys. 2. Mikrofotografie SEM próbek: a) zaprawa normowa, b) zaprawa z dodatkiem $10 \mathrm{~g}$ odpadowych tworzyw polimerowych, c) $20 \mathrm{~g}$, d) $30 \mathrm{~g}$

Fig. 2. SEM micrographs of specimen: a) standard mortar, b) mortar with $10 \mathrm{~g}$ polymer materials added, c) $20 \mathrm{~g}$, d) $30 \mathrm{~g}$ 

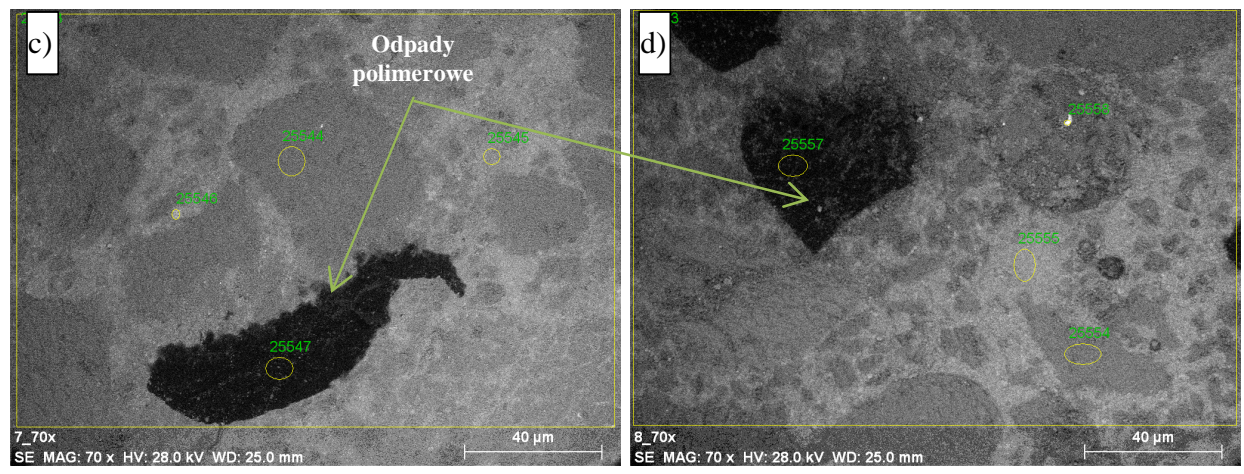

Rys. 2. c.d. Mikrofotografie SEM próbek: a) zaprawa normowa, b) zaprawa $\mathrm{z}$ dodatkiem $10 \mathrm{~g}$ odpadowych tworzyw polimerowych, c) $20 \mathrm{~g}$, d) $30 \mathrm{~g}$

Fig. 2. cont. SEM micrographs of specimen: a) standard mortar, b) mortar with $10 \mathrm{~g}$ polymer materials added, c) $20 \mathrm{~g} \mathrm{~d}) 30 \mathrm{~g}$

a)

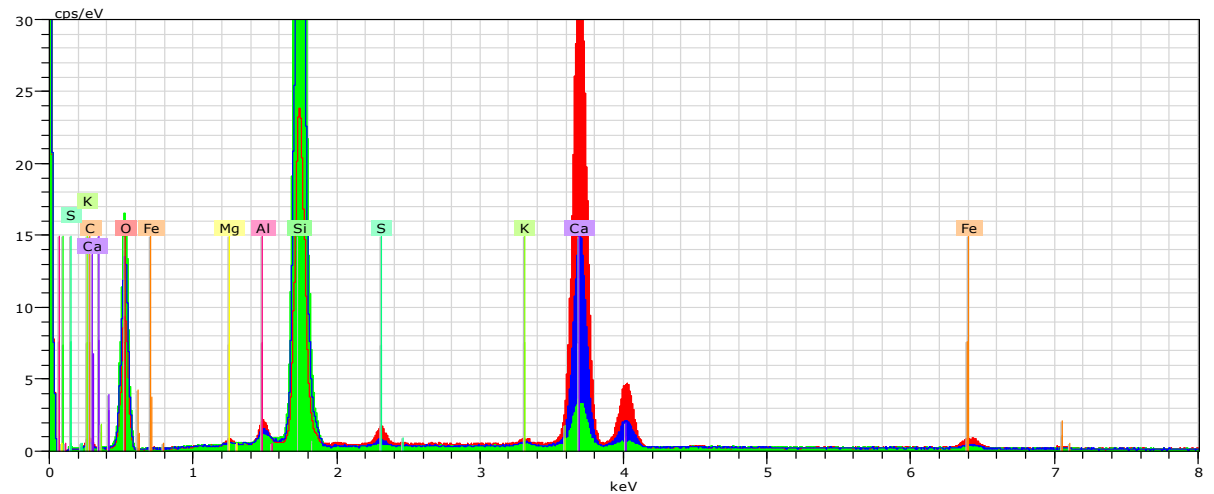

b)

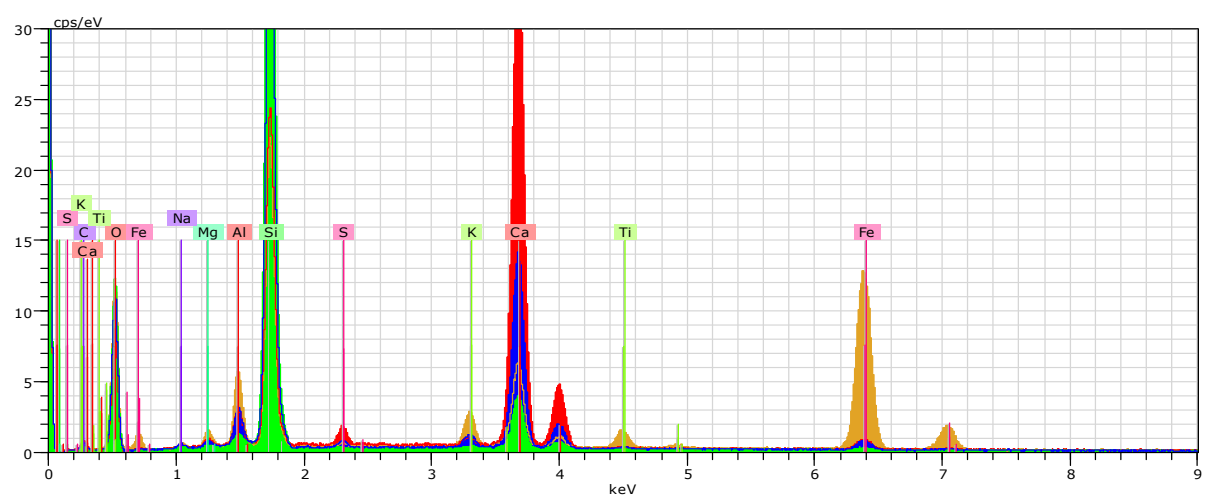

Rys. 3. Widma składu pierwiastkowego badanych mikroobszarów (serie $\mathrm{PK} \div 3$ )

Fig. 3. Spectra of the elemental composition of the tested microareas (series $\mathrm{PK} \div 3$ ) 
c)

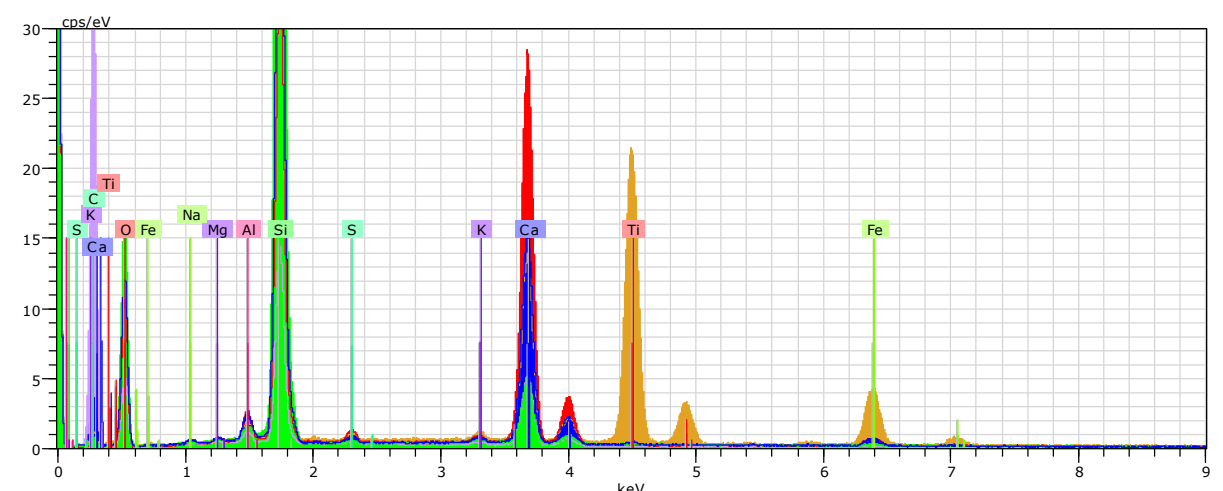

d)

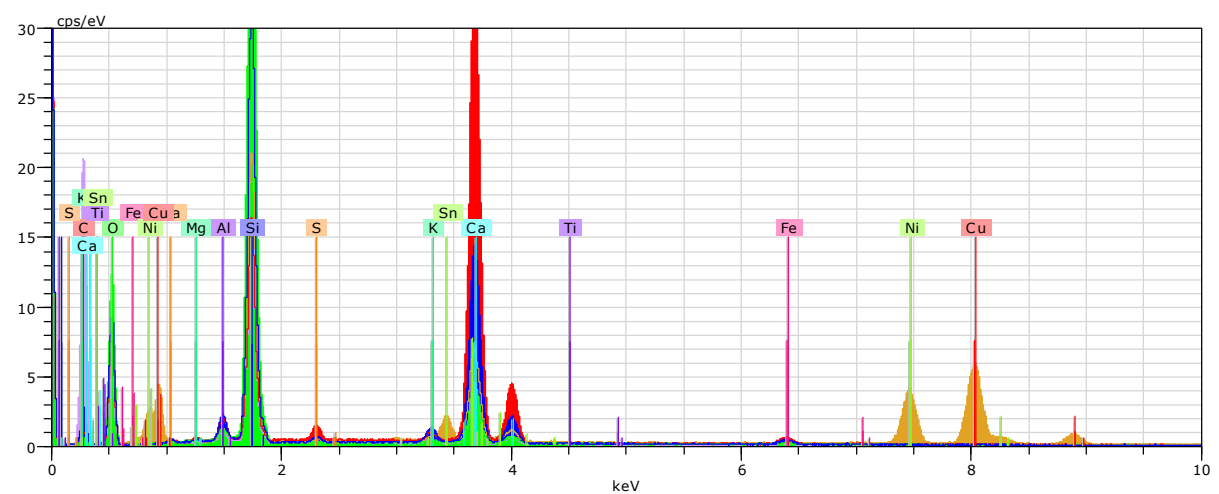

Rys. 3. c.d. Widma składu pierwiastkowego badanych mikroobszarów (serie $\mathrm{PK} \div 3$ )

Fig. 3. cont. Spectra of the elemental composition of the tested microareas (series $\mathrm{PK} \div 3$ )

W kolejnym etapie badań określono wytrzymałość na ściskanie próbek zaprawy normowej, a także zapraw zawierających polimerowe tworzywa odpadowe. Jak wynika z wyników przeprowadzonych badań (rys. 4) zaprawa normowa uzyskała średnią wytrzymałość na ściskanie równą 56,5 MPa. Próbki zawierające odpady polimerowe wykazały podobne lub wyższe wartości wytrzymałości na ściskanie w porównaniu z zaprawą normową. Dodanie 10 i 20 g odpadu spowodowało wzrost średniej wytrzymałości na ściskanie próbek odpowiednio o $1,8 \%(57,5 \mathrm{MPa})$ i 4,4\% (59 MPa), natomiast próbki z dodatkiem $30 \mathrm{~g}$ tworzyw odpadowych uzyskały taką samą wytrzymałość jak zaprawa normowa. 


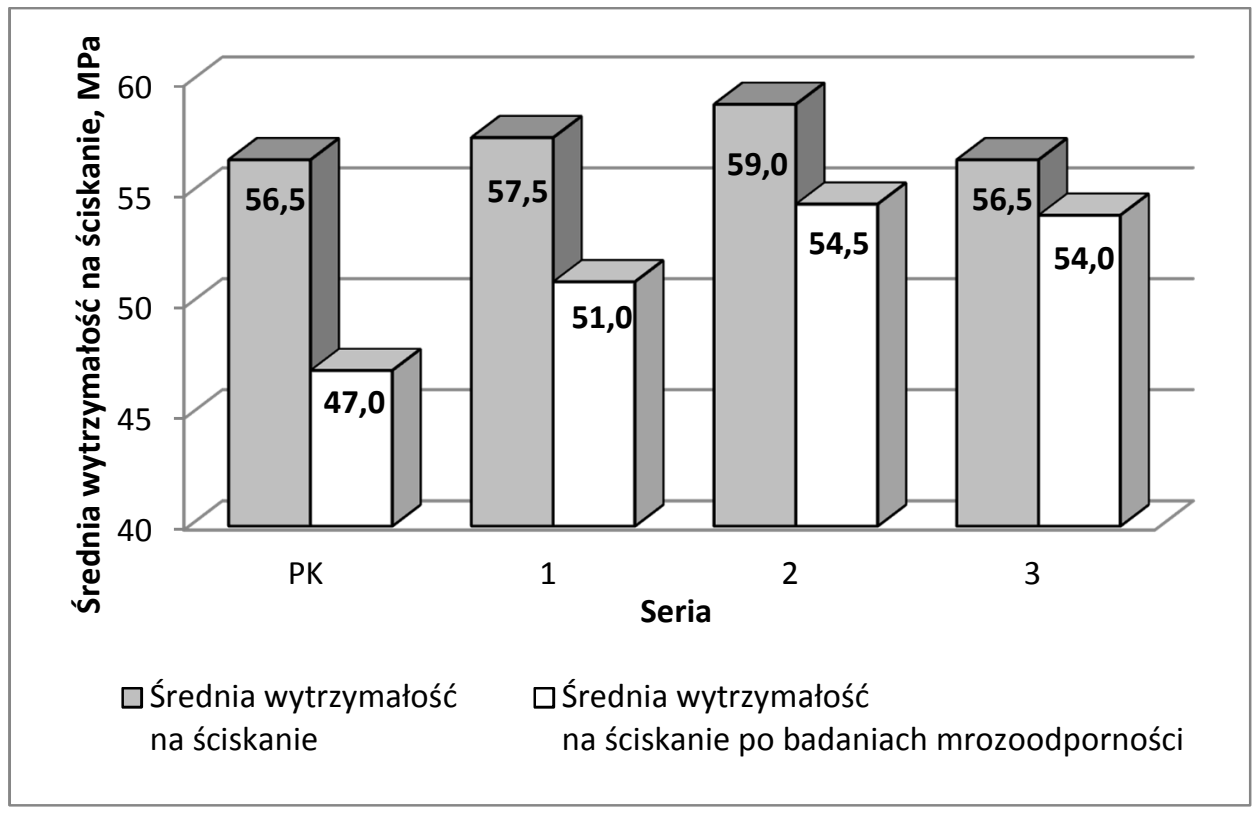

Rys. 4. Właściwości mechaniczne próbek

Fig. 4. Mechanical properties of the specimen

Przeprowadzone badania umożliwiły zarówno na określenie spadku wytrzymałości na ściskanie, jak również ubytku masy próbek po badaniach mrozoodpornościowych polegających na 25 cyklach zamrażania oraz rozmrażania próbek. Jak wynika $\mathrm{z}$ danych przedstawionych w tabeli 2 oraz na rys. 4 , próbki z zawartością polimerowych materiałów odpadowych po badaniach mrozoodpornościowych wykazują znacznie niższy spadek wytrzymałości na ściskanie wynoszący od 4,42 do $11,30 \%$, w porównaniu z zaprawą normową, która utraciła prawie $17 \%$ swojej wytrzymałości na ściskanie. Próbki te wykazały również większy ubytek masy niż próbki z zaprawy normowej wynoszący maksymalnie $0,25 \%$ w przypadku $30 \mathrm{~g}$ zawartości odpadowych tworzy polimerowych.

Tabela 2. Właściwości mechaniczne próbek po badaniach mrozoodporności

Table 2. The mechanical properties of specimen after frost resistance tests

\begin{tabular}{|c|c|c|c|}
\hline Seria & $\begin{array}{c}\text { Zawartość } \\
\text { tworzyw polimero- } \\
\text { wych, } \\
\text { g }\end{array}$ & $\begin{array}{c}\text { Spadek } \\
\text { wytrzymałości, } \\
\text { \% }\end{array}$ & $\begin{array}{c}\text { Ubytek masy po } \\
\text { badaniach } \\
\text { mrozoodporności } \\
\text { \% }\end{array}$ \\
\hline PK & - & 16,81 & 0,05 \\
\hline 1 & 10 & 11,30 & 0,21 \\
\hline 2 & 20 & 7,63 & 0,23 \\
\hline 3 & 30 & 4,42 & 0,25 \\
\hline
\end{tabular}


Jak wykazały wyniki przeprowadzonych badań nasiąkliwości (rys. 5) zaprawy cementowe zawierające tworzywa polimerowe charakteryzują się niewiele większą nasiąkliwością od zaprawy normowej - maksymalnie o ok. 2,7\% w przypadku serii 3.

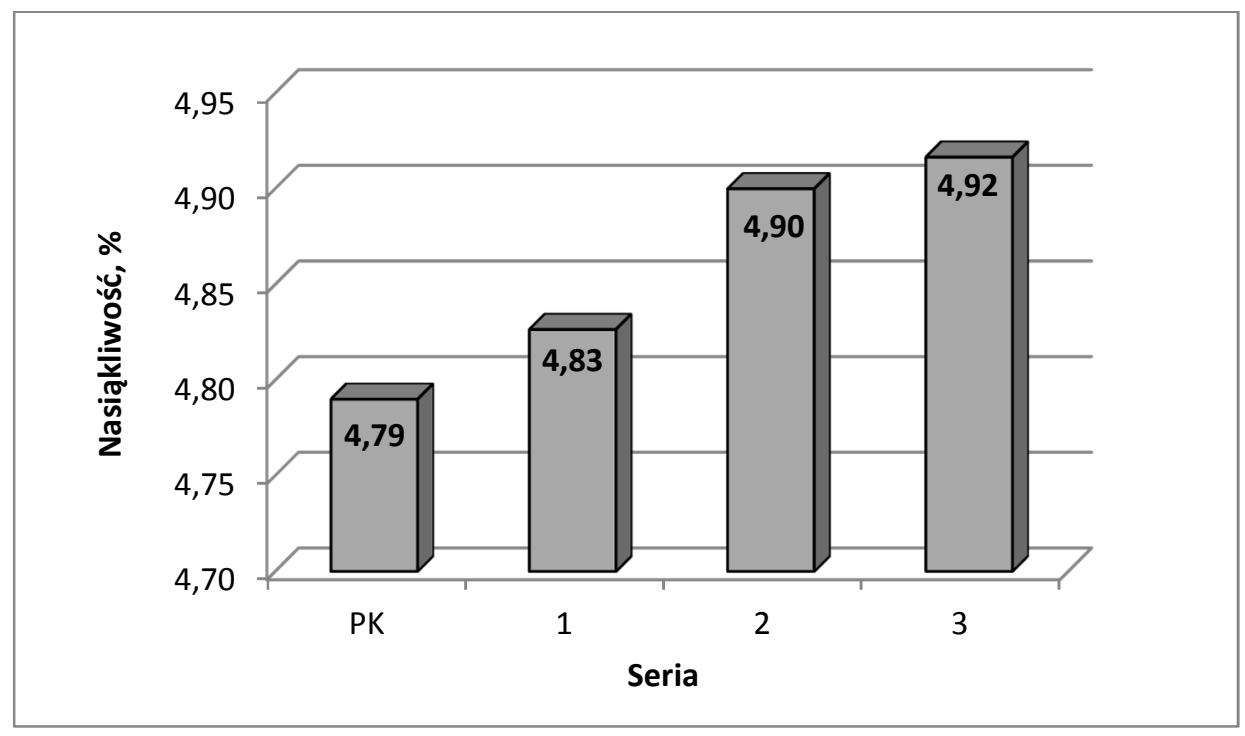

Rys 5. Nasiąkliwość zapraw cementowych

Fig. 5. Absorbability of cement mortars

\section{Wnioski}

Badania wykazały, że zastosowanie odpadowych tworzyw polimerowych (mieszanina PE i PP) może wpływać korzystnie na ich właściwości mechaniczne. Najwyższą wytrzymałość na ściskanie (59 MPa) uzyskały zaprawy zawierające w swoim składzie 20 g odpadów polimerowych, wyższą o 2,5 MPa od zaprawy normowej. Najmniejszy spadek wytrzymałości na ściskanie próbek poddanych badaniu mrozoodporności uzyskały próbki wykonane z zapraw zawierających 30 g odpadów. Nasiąkliwość wszystkich badanych próbek była na podobnym poziomie $(4,79 \div 4,92 \%)$.

\section{Literatura}

[1] Yuan F., Shen L., Li Q.: Emergy analysis of the recycling options for construction and demolition waste, Waste Management, 31, 2011, pp. 2503-2511.

[2] Binici H.: Effect of crushed ceramic and basaltic pumice as fine aggregates on concrete mortars properties, Construction and Building Materials, 21, 2007, pp. 1191-1197. 
[3] Jura J., Halbiniak J., Ulewicz M.: Wykorzystanie odpadów ceramiki użytkowej i sanitarnej w zaprawach cementowych, Materiały Ceramiczne, T.67 nr 4, 2015, s. 438-442.

[4] Park S., Lee B.: Studies on expansion properties in mortar containing waste glass and fibers, Cement and Concrete Research, 34, 2004, pp. 1145-1152.

[5] Lia G., Garricka G., Eggersb J., Abadieb C., Stubblefieldc M., Pang S.: Waste tire fiber modified concrete, Composites: Part B, 35, 2004, pp. 305-312.

[6] Panesar D. K., Shindman B.: The mechanical, transport and thermal properties of mortar and concrete containing waste cork, Cement \& Concrete Composites, 34, 2012, 982-992.

[7] Wang S., Miller A., Llamazos E., Fonseca F., Baxter L.: Biomass fly ash in concrete: mixture proportioning and mechanical properties, Fuel, 87, 2008, 365-371.

[8] Ismail Z. Z., Al-Hashmi E. A.: Use of waste plastic in concrete mixture as aggregate replacement, Waste Management, 28(11):2041-7, 2008.

\section{USE OF THE WASTE MATERIALS IN CEMENT MORTARS}

\section{S u m m a r y}

The article briefly characterized the problem of the increasing amount of waste and problems with their management, use, and recycling. Presented literature reports of laboratory tests and on a larger scale reuse in building the building waste and the waste from other sectors of the economy. In the experimental part examined the possibility of using waste polymer materials with the fragmentation of bottle caps made of polypropylene and polyethylene. By means of the research it has been characterized impact of the quantity of the waste material on physical and mechanical properties of samples, such as compressive strength, frost resistance, loss of weight and absorbency of created materials. The studies were made according to standard specimens of the mortar consisting of sand, cement and water, and the specimens with added of the polymer material waste in an amount of $10 \div 30 \mathrm{~g}$. Tests were performed according to standards. With the use of a scanning electron microscope obtained micrographs and spectrum of the mortar surface. The best mechanical properties were obtained samples with $20 \mathrm{~g}$ of polymeric material. The samples with this proportions obtained the highest compression strength (59 MPa). All specimens containing polymeric materials obtained smaller decrease compressive strength after frost resistance test. The smallest decline in strength had specimens with $30 \mathrm{~g}$ of polymer materials. In the studied specimens the lowest water absorption (4.79\%) obtained samples of standard mortar but other samples had similar results $(4.83 \div 4.92 \%)$.

Keywords: polymer materials, use of waste, recycling, polymer waste

DOI:10.7862/rb.2016.269

Przestano do redakcji: $30.06 .2016 r$.

Przyjęto do druku: 20.12.2016 r. 